\title{
DIVERGERCIA EN LA ESTRATEGIA SOBRE EL PROBLEMA MUNDIAL DE LAS DROGAS ERTRE LA UE Y AMÉRICA LATINA Y CARIBE
}

\author{
Convergence and divergence in the strategy on \\ the world drug problem between the European \\ Union and Latin America and the Caribbean
} Autor

El problema mundial de las drogas se ha convertido en un objeto destacado de diálogo político y cooperación en las relaciones entre la UE y América Latina y Caribe. Las relaciones en este ámbito se basan en el principio de responsabilidad compartida consagrado en los principales instrumentos internacionales y han ido ampliando sus áreas de trabajo, desde los enfoques vinculados a la seguridad a otros que amplían su alcance al desarrollo alternativo y a las políticas sociales de prevención y de salud. Las visiones y enfoque de los diversos países y actores implicados se han ido aproximando, pero están además determinadas por las diferentes estrategias de la ONU y los tratados multilaterales, la OEA, las sucesivas estrategias Europeas contra las drogas y las estrategias subregionales que se han creado en el área Andina y en América del Sur. Existen dificultades a la hora de coordinar las operaciones y programas debido a que la cooperación está muy fragmentada y a posicionamientos ideológicos que oscilan entre estrategias prohibicionistas y otras que defienden la despenalización y la regulación total o parcial de su producción y distribución. Esas diferencias se pusieron de manifiesto en la Sesión especial de las Naciones Unidas sobre las Drogas celebrada en abril de 2016 e impidieron avances significativos en la agenda internacional.

Unión Europea; América Latina; drogas; diálogo político; cooperación.

European Union; Latin America; drugs; political dialogue; cooperation.

Key mords 
The world drug problem has become a vital subject in the political dialogue and cooperation between the European Union and Latin America and the Caribbean. International relations in this regard are based on the principle of shared responsibility, which has been enshrined on the most relevant international instruments, and its focus areas have been extending from approaches related to security to others such as alternative development and health and prevention social policies. The approaches and views of countries and actors involved have been converging, and they are also determined by multiple strategies that come from the United Nations and multilateral treaties, the OAS, anti-drug European strategies and sub-regional strategies that have been created in the Andean area and South America. Coordination of programs and operations is difficult since cooperation is very fragmented and also due to the existence of ideological approaches that either favor prohibition or argue for decriminalization and the total or partial regulation of its production and distribution. Such differences were visible in the UN General Assembly Special Session on Drugs that was held in April 2016, which hindered significant progress of the international agenda on drugs.

La lucha contra el tráfico ilegal organizado de sustancias estupefacientes y psicotrópicas y los delitos asociados es un claro ejemplo de riesgo global en el que la cooperación internacional se hace imprescindible. América del Sur produce casi toda la cocaína del mundo con Colombia, Bolivia y Perú como principales proveedores y los mercados más grandes son Estados Unidos y la Unión Europea (UE). Los europeos consumen una cuarta parte de la producción mundial total de cocaína, justo detrás de los Estados Unidos. Por otra parte, la UE es también creciente productora de drogas sintéticas que viajan en dirección contraria, así como de precursores químicos que, desviados ilegalmente, se utilizan para la elaboración de las drogas de origen natural (World Drug Report 2016). Es por ello que la cuenca del Atlántico concentra algunas de las principales rutas para el tráfico de drogas en el mundo que han ido diversificándose y haciéndose más complejas (Ayuso \& Viilup, 2014). En consecuencia, el problema mundial de las drogas se ha convertido en un objeto destacado de diálogo político y cooperación en las relaciones entre la UE y América Latina y Caribe (ALC).

Las relaciones en este ámbito se basan en el principio de responsabilidad compartida que está consagrado en los principales instrumentos internacionales, pero cuyo alcance no está bien delimitado y se interpreta de forma distinta según los actores. El diálogo y la cooperación que ha surgido entre ambas regiones ha ido evolucionando y ampliando sus áreas de trabajo, desde los iniciales enfoques muy vinculados a la seguridad a otros que amplían su alcance al desarrollo alternativo y a las políticas sociales de prevención y de salud. En este proceso de intercambio, las visiones y enfoque de los diversos países y actores implicados se han ido aproximando, pero no son idénticas. Estas posiciones están además determinadas por las estrategias a nivel internacional encabezadas por la ONU y los tratados multilaterales, las estrategias regionales como la hemisférica a través de la Organización de Estados Americanos (OEA), las sucesivas estrategias Europeas contra las Drogas y las estrategias sub-regionales que se han creado en el área Andina y en América del Sur que se analizarán en este ensayo ${ }^{1}$.

l No se abordará en este texto la estrategia de Seguridad centroamericana y la mexicana específicamente, ya que no participan en un diálogo subregional específico con la UE, aunque sí su participación en la agenda hemisférica y en la relación bi-regional UE-ALC y la global de Naciones Unidas.

\section{Los europeos \\ consumen una \\ cuarta parte de la producción mundial de cocaína. Por otra parte, la UE es creciente productora de drogas sintéticas que viajan en dirección contraria}


Aunque se han ido estableciendo sinergias entre esos diferentes espacios existen dificultades a la hora de coordinar las operaciones y programas. En parte es debido a que la cooperación está muy fragmentada y las políticas relacionadas con la seguridad son muy sensibles, pero también hay dificultades derivadas de diferentes posicionamientos ideológicos que oscilan entre estrategias prohibicionistas, de guerra declarada a las drogas, y otras estrategias que defienden la despenalización y la regulación total o parcial de su producción y distribución (Pedraza Rosales, 2014). Como veremos, esas diferencias se pusieron de manifiesto en la Sesión especial de las Naciones Unidas sobre las Drogas (UNGASS, por sus siglas en inglés) celebrada en abril de 2016 (Tokatlian y Comini, 2016) e impiden que se den pasos significativos para transformar el actual régimen internacional sobre el tratamiento de las drogas ${ }^{2}$.

El escenario internacional presenta una complejidad cada vez mayor en cuanto el tipo y variedad de drogas existentes, las rutas del narcotráfico y su conexión con otros crímenes internacionales como el tráfico de armas, de personas o el lavado de dinero. Es por ello que ya no es posible reducirlo a un dilema entre modelos de políticas reduccionistas: bien enfocado a la persecución de productores y consumidores, como fue el de la guerra a las drogas declarada por Estados Unidos en la época de la Administración Bush padre, o bien únicamente atendiendo a las causas y consecuencias del consumo, como se pretendió desde algunos países europeos. El fracaso de ambos modelos (Gratius, 2012), ha conducido a un debate acerca de si es necesario buscar un cambio de paradigma en la forma en cómo se afronta ese problema mundial de forma más multidimensional, pero aún no hay un consenso sobre cómo lograrlo. A continuación se analizará la evolución de las estrategias regionales de lucha contra las drogas en América Latina y en Europa, así como las políticas e instrumentos de cooperación entre ambas regiones. Finalmente se terminará haciendo un balance de como las convergencias y divergencias están incidiendo en la estrategia global que lidera Naciones Unidas.

\section{Cooperación hemisférica y subregional en las Américas}

Debido a la inestabilidad que crea en la región, la lucha contra el narcotráfico no podía dejar de ocupar un lugar preeminente en la Agenda Hemisférica. El tráfico ilícito de narcóticos y el crimen organizado que lo acompaña no sólo ha agravado los problemas de gobernabilidad dentro de los Estados, sino que también ha generado tensiones entre ellos que repercuten negativamente en los procesos de integración y cooperación regional (Ayuso \& Beltrán, 2007). Por la gran repercusión que el problema tiene en la Zona Andina como centro de producción de la hoja de coca, es lógico que fueran estos países los primeros que intentaron fomentar la cooperación regional en esos temas, pero pronto pasó a ser una preocupación hemisférica en la OEA. Más adelante fue objeto de la agenda sudamericana a través de la Unión Sudamericana de Naciones (UNASUR), en busca de una mayor autonomía de los Estados Unidos para afrontar el problema desde una perspectiva latinoamericana, que busca aportar una estrategia distinta a la tradicional. Es en esa línea que la cooperación europea ha sido vista como una alternativa a

2 Este está basado en la Convención Única sobre Estupefacientes de las Naciones Unidas de 1961, modificada por el Protocolo de 1972, el Convenio sobre Sustancias Sicotrópicas de 1971 y la Convención de Viena contra el tráfico ilícito de estupefacientes y sustancias psicotrópicas de 1988. Además de los sucesivas Declaraciones Políticas y Planes de Acción sobre Cooperación Internacional adoptados en el marco de la Comisión de Estupefacientes de las Naciones Unidas.

La cooperación está fragmentada y las políticas relacionadas con la seguridad son sensibles; también hay dificultades derivadas de diferentes posicionamientos ideológicos 
la influencia hegemónica de Estados Unidos y se han establecido líneas de cooperación, aunque aún no se puede decir que haya un consenso bi-regional totalmente compartido, ni mucho menos llevado a la práctica de forma consistente.

\subsection{Estrategia Hemisférica Antidrogas}

Hasta mediados de los años 80 la OEA no incluía la lucha contra el narcotráfico como una estrategia regional. Las políticas nacionales eran las responsables de enfrentar el problema bajo las directrices de la acción de Naciones Unidas (Ruiz-Cabañas, 1998). Sin embargo, al iniciarse dicha década el narcotráfico ya había adquirido unas dimensiones en la región que la convertiría en la principal productora y consumidora de drogas. La primera respuesta hemisférica fue la convocatoria de la conferencia interamericana especializada sobre narcotráfico por la Asamblea General en 1984. Esta iniciativa acompañaba la política de la Administración de Reagan que, en 1983, lanzó la guerra contra las drogas, incluyendo medidas de presión sobre países productores y de tránsito. Así, el Congreso de los Estados Unidos acabaría estableciendo en 1986 un sistema de certificación unilateral de países, el cual suponía la retirada de la ayuda financiera a aquellos Estados que, según su criterio no cumplieran con los compromisos internacionales en la lucha contra el cultivo, producción y el tráfico ilegal de drogas. La influencia norteamericana en el combate contra el narcotráfico fue desde entonces determinante y la mayoría de las acciones antinarcóticos en el hemisferio por entonces fueron diseñadas y financiadas por Estados Unidos (Interamerican Dialogue, 2001). Este ascendiente, de inspiración represiva, fue acompañado de sucesivos programas de cooperación dotados de una financiación creciente ${ }^{3}$.

Los principales resultados de la primera conferencia interamericana sobre combate al narcotráfico, celebrada en abril de 1986 en Río de Janeiro, fueron el Programa Interamericano de acción contra el consumo, la producción y el tráfico ilícitos de estupefacientes y sustancias psicotrópicas o Programa de Acción de Río, así como una propuesta de creación de una comisión de control. Dicho programa no era un convenio jurídico, sino un acuerdo político que abogaba por un consenso en la definición de las políticas y una coordinación en su aplicación de acuerdo a los parámetros establecidos en los instrumentos multilaterales adoptados en el marco de las Naciones Unidas. En la línea de los objetivos del posterior Convenio de Viena de Naciones Unidas de 1988 contra el tráfico ilícito de estupefacientes y sustancias psicotrópicas, se trataba de una estrategia fundamentalmente dirigida a la represión del tráfico ilícito de drogas. La misión del plan era contribuir al cumplimiento de la estrategia global contra el narcotráfico mediante mecanismos de control específico, cooperación técnica para perfeccionar los instrumentos jurídicos e institucionales de los países de América y el seguimiento periódico de la información proporcionada por los Estados. A pesar de que se reconocía que la lucha contra el narcotráfico debía formar parte de un programa de desarrollo económico, lo cierto es que las medidas propuestas únicamente recogían la reducción de cultivos y la interdicción del comercio ilícito sin propuestas sobre medidas complementarias dirigidas a abordar las causas estructurales en el origen del problema.

3 Así la Iniciativa Andina de la Administración Bush padre de 1989 (2,2 millones de dólares en 5 años), fue seguida del Plan Colombia del Presidente Clinton en 2000 (1,6 millones de dólares) y sucedida por la Iniciativa Regional Andina de Presidente Bush en 2001 (más de 700 millones anuales).

Las medidas
recogían la
reducción de
cultivos y la
interdicción del
comercio ilícito sin
propuestas sobre
medidas dirigidas a
abordar las causas
estructurales
en el origen del
problema

Las medidas recogian la reducción de cultivos y la interdicción del comercio ilícito sin propuestas sobre medidas dirigidas a abordar las causas estructurales problema 
En 1986 la Asamblea General de la OEA creó la Comisión Interamericana para el Control del Abuso de Drogas (CICAD) ${ }^{4}$ con la función principal de establecer los mecanismos de cooperación para fortalecer los sistemas nacionales de lucha contra el abuso, tráfico y producción ilícita de drogas 5 . La acción de la CICAD se configuró como complementaria a la de los Estados y entendida como acciones de apoyo técnico para desarrollar las capacidades jurídicas, administrativas y operativas de los gobiernos de las políticas nacionales. Pero, al tiempo, se conformaba como un mecanismo de diálogo y cooperación entre los países miembros de carácter paritario ${ }^{6}$. No entraba dentro de las competencias de la CICAD la creación de nuevos instrumentos convencionales, sino que, partiendo de los compromisos vigentes, se proponía coadyuvar a los esfuerzos nacionales en el cumplimiento de sus obligaciones mediante mecanismos e instrumentos de cooperación complementarios para llevarlos a la práctica. Las funciones de la CICAD quedaban repartidas en tres grandes grupos: en primer lugar, la recopilación y difusión de datos, ayudando a crear sistemas de recopilación estandarizados ${ }^{7}$. En segundo lugar, la investigación y capacitación en temas específicos. Así, la formación de funcionarios de la Administración Antidrogas, de los cuerpos aduaneros o las guardias costeras y portuarias o la creación de la Escuela Regional de Inteligencia Antidrogas (ERCAIAD), la capacitación de jueces y fiscales, la capacitación de personal bancario para luchar contra el lavado de activos o el fortalecimiento de las unidades de inteligencia financiera y la creación de programas de maestría sobre drogodependencia, capacitación de mediadores y profesionales de la salud. Finalmente, se buscaba la armonización de la legislación antidroga, mediante la negociación de recomendaciones a través de instrumentos no vinculantes jurídicamente ${ }^{8}$.

Los principios del Programa de Río fueron actualizados mediante el Programa de Acción de Ixtapa elaborado en México el 20 de abril de 1990․ En éste ya aparecieron mencionados tanto el principio de solidaridad internacional, como el de responsabilidad compartida y se reconocía la vinculación entre oferta, demanda y distribución ilícita de drogas y las condiciones económicas, sociales y culturales de los países afectados. Por tanto se entendía que el combate al problema debía ser integral, aunque no se proponían nuevos instrumentos que incorporasen dicha dimensión. Otra recomendación fue la necesidad de evaluar los resultados de los primeros programas

4 La Declaración de Guatemala "Alianza de las Américas contra el Narcotráfico” AG/Res.817 (XVI-0/86) de 15 noviembre 1986. En esta misma sesión la Asamblea General de la OEA adoptó formalmente el Programa de Acción de Río.

5 Inicialmente los miembros de la CICAD, eran sólo 11, pero en la actualidad participan casi todos los miembros de la OEA. La financiación de las actividades de la CICAD corre a cargo de las contribuciones voluntarias de los Estados donantes.

6 Ruiz-Cabañas (1998) señaló como desde los inicios este enfoque de cooperación multilateral paritaria se contraponía a la estrategia unilateral estadounidense que introdujo ese mismo año el proceso de certificación.

7 Por ejemplo, mediante la elaboración de un compendio anual de datos sobre la oferta (CICDAT) o con la realización de Estudios Uniformes sobre la extensión del consumo (SIDUC). En el año 2000 se incorporó a la CICAD el Observatorio Interamericano sobre Drogas (OID).

8 Como el reglamento modelo sobre precursores químicos de 1990, el de delitos de lavado de activos relacionados con el tráfico ilícito de drogas de 1992 o el de proliferación y comercio internacional de armas de fuego de 1997. También colabora en general en la elaboración de los Planes Nacionales Antidroga (PNA) en la mayoría de los países del hemisferio.

9 Elaborada inmediatamente después de la Declaración de la Conferencia Cumbre ministerial mundial para reducir la Demanda de Drogas y Combatir la amenaza de la cocaína celebrada en Londres en abril de 1990.

\section{La CICAD se conformó como un mecanismo de diálogo y cooperación entre los países miembros de carácter paritario}


de desarrollo alternativo ${ }^{10}$ al cultivo de drogas que habían comenzado a ser impulsados y se encomendó a la CICAD consultar con los organismos implicados.

Para avanzar en el ámbito de la reducción de la demanda se elaboró el Programa Interamericano de Quito de 1990 en el que se trataba de establecer unas bases de referencia para las políticas nacionales de prevención e incluía la educación preventiva integral contra el uso de drogas. Además de servir para reforzar las capacidades de las instituciones nacionales, se quería facilitar la cooperación internacional en esa materia. Más tarde, se organizó la Conferencia Ministerial de Lavado de dinero e instrumentos del delito en Buenos Aires en diciembre de 1995, donde se aprobó una declaración de principios y un plan de Acción ${ }^{11}$. Este último contemplaba la colaboración judicial y proponía el establecimiento de un mecanismo de evaluación permanente en el seno de la OEA, que no se llegó a implementar.

Una renovación general del Programa de Acción llegaría en 1996, cuando la Asamblea general de la OEA aprobó una nueva "Estrategia Antidrogas del Hemisferio"12, que incorporaba ya plenamente el criterio de responsabilidad compartida teniendo en cuenta las "capacidades y recursos nacionales disponibles". Además esta actualización asumía la creciente complejidad de un problema con múltiples derivaciones e incorporaba nuevos elementos en los que se apreciaba la progresiva erosión de las diferencias entre países productores, de tránsito y de destino. Pero el aspecto más novedoso fue la incorporación de un capítulo específico dedicado a los mecanismos de control, aunque mayoritariamente se refería a controles ya existentes de actividades delictivas de narcotráfico. La estrategia del 96 señalaba la importancia de la reducción de la demanda, que es la fuerza impulsora de la producción, y que cada país tiene la responsabilidad de abordar el problema teniendo en cuenta las condiciones culturales, sociales y económicas de cada grupo de población. Se instaba a establecer mecanismos de participación ciudadana y a fortalecer la educación y la prevención. También se recomendaba a los Estados introducir la variable ecológica del problema. La responsabilidad del cumplimiento de los objetivos recaía en el nivel nacional, pero se incluía una llamada a compartir experiencias.

En el terreno de la reducción de la oferta, se reconocía la existencia de nuevas categorías de drogas especialmente las de origen sintético que se sumaban a las de origen natural. Mientras para estas últimas se planteaba el recurso a programas de desarrollo alternativo, para las primeras únicamente se contempla el control y la interdicción. Sean cuales sean el tipo de medidas a tomar, se afirmaba que la determinación, definición y aplicación de las mismas era "responsabilidad exclusiva de cada Estado, conforme a sus programas nacionales y sus ordenamientos jurídicos internos". Dado que no se establecían metas ni objetivos concretos, las medidas de control propuestas fueron dirigidas al intercambio de información, el desarrollo de los sistemas jurídicos adecuados para controlar y castigar los delitos, la armonización de legislaciones, la capacitación y los controles fronterizos.

La estrategia recomendaba el fortalecimiento de la CICAD con la ampliación de su mandato para incluir nuevas substancias e incorporar delitos considerados conexos como el lavado de

10 Según la Oficina de Naciones Unidas contra la Droga y el Delito (UNODC, por sus siglas en inglés), el Desarrollo Alternativo es un proceso destinado a reducir y eliminar el cultivo de plantas que contengan estupefacientes, así como sustancias sicotrópicas ofreciendo como alternativas otros cultivos.

11 La conferencia ministerial obedecía al mandato de la Primera cumbre de las Américas celebrada en Miami en diciembre de 1994

12 Aprobada por la CICAD en Buenos Aires, Argentina, el 16 de octubre de 1996 en el 10 aniversario de su creación.
Una renovación general del Programa de Acción llegaría en 1996, cuando incorporó ya plenamente el criterio de responsabilidad compartida 
activos, el tráfico de armas, la cooperación marítima y seguridad portuaria, la delincuencia internacional organizada e incluso la violencia juvenil, entre otros ${ }^{13}$. Esto implicó la ampliación de los mecanismos de control y de armonización de legislaciones a esos nuevos ámbitos incorporados. En mayo de 1998 la CICAD aprobó el Plan de Acción para la Implementación de la Estrategia Antidrogas en el Hemisferio. Este contemplaba medidas en el plano de la reducción de la demanda y de la oferta, proponiendo el establecimiento de nuevos mecanismos de recogida de información para facilitar la coordinación de las políticas nacionales y mecanismos de control para la armonización de procedimientos entre los estados y con otras organizaciones internacionales.

La II Cumbre de la Américas de Santiago de Chile en 1998, puso de nuevo el énfasis en los mecanismos de control y encargó a la CICAD elaborar un sistema estandarizado para medir periódicamente las acciones antidrogas de los 34 miembros de la CICAD. El Mecanismo de Evaluación Multilateral (MEM) creado en 1999 está compuesto por un grupo de expertos intergubernamentales (GEG) que ha definido, a través de 51 indicadores que se van actualizando ${ }^{14}$, los componentes de las políticas nacionales antidrogas que han de ser objeto de seguimiento y genera periódicamente informes para medir los esfuerzos realizados, en el nivel nacional, regional y hemisférico. Esta iniciativa de seguimiento de carácter paritario permitió dar respuesta alternativa al sistema unilateral que habían establecido los Estados Unidos para otorgar la certificación y había sido objeto de numerosas críticas, ya que era la base para la aplicación de medidas de retorsión en materia de ayuda internacional. El que Estados Unidos aceptara patrocinar la iniciativa supuso un gran paso para el sistema multilateral regional, aunque periódicamente siga haciendo públicas sus propias valoraciones unilaterales, a veces no coincidentes con la CICAD.

Los expertos independientes encargados de hacer la revisión reciben la información de los Estados pero también pueden consultar otras fuentes aunque las visitas in situ son de carácter excepcional. Los informes se basan en cuatro apartados principales: fortalecimiento institucional de los planes y programas antidrogas; reducción de la demanda; programas de reducción de la oferta, la producción y desarrollo alternativo; mejora de las medidas de control del tráfico ilícito de drogas, armas de fuego y lavado de activos de la legislación; y compromiso general. Los expertos elaboran recomendaciones públicas en el nivel nacional, regional y hemisférico y en caso de incumplimiento reiterado de las recomendaciones se prevé el establecimiento de un diálogo con el país para incentivarlo a solicitar el apoyo que necesite. En el año 2000 se creó el Observatorio Interamericano sobre Drogas (OID) para asesorar a los estados miembros de la CICAD en la elaboración de las estadísticas e informaciones necesarias para hacer un correcto seguimiento que permita estudios comparables ${ }^{15}$ y hacer su difusión. Además debe servir como mecanismo de alerta ante posibles cambios en la operativa de los narcotraficantes o ante la aparición de nuevos fenómenos relacionados. También se estableció un Fondo de solidaridad

13 El Estatuto de la CICAD se modificó en el XX periodo de sesiones celebrado en Buenos Aires en octubre de 1996 y adoptado por la Asamblea General de la OEA AG/RES. 1457 celebrado en Lima en junio de 1997.

14 En la primera revisión sólo habían 61 indicadores, pero se fueron incrementando hasta 82 a través de la tres rondas de evaluación cada dos años hasta ahora realizadas: (1999-2000) (2001-2002) (2003-2004) (2005-2007).

15 El OID consta de un Banco Interamericano de Datos sobre Drogas, el Sistema Interamericano de Información de Drogas (IADIS) y un sistema de intercambio electrónico de información (RETCOD/NDC).

Que Estados Unidos aceptara patrocinar la iniciativa supuso

un gran paso para el sistema multilateral regional, aunque siga haciendo públicas sus propias valoraciones unilaterales 
que tiene como finalidad facilitar la participación de aquellos Estados que no cuentan con los medios financieros suficientes ${ }^{16}$.

Durante la III Cumbre de las Américas celebrada en Canadá en abril de 2001, tras la primera ronda de evaluación del MEM, se aprobó el Plan de Acción de Quebec, que dio un mandato a la CICAD para elaborar un programa de tres años que permitiera establecer el nivel de asistencia necesaria, al tiempo que hacia una llamada al Banco Interamericano de Desarrollo (BID) a incrementar la colaboración con recursos financieros. Los primeros informes hemisféricos del MEM daban cuenta también de los efectos limitados de los programas de desarrollo alternativo, aunque reconocía la falta de mecanismos de evaluación de la eficacia y el impacto de dichos proyectos. En concreto, se apuntaba a la falta de continuidad en los programas ante la ausencia de resultados a corto plazo como uno de los factores determinantes de la falta de resultados de medio y largo plazo, que son en realidad los propios de los proyectos productivos de desarrollo rural. Por ello se hizo un llamamiento, tanto a países productores, como consumidores para apoyar los programas de desarrollo alternativo con un enfoque más estratégico (Ayuso \& Beltrán, 2007).

Esta referencia, que ilustra el principio de corresponsabilidad, contrasta, sin embargo con el escaso peso que en la cooperación de la CICAD y de la OEA en general, se ha dado al ámbito del desarrollo alternativo en la práctica. La interpretación del mencionado principio parece reducida al compromiso de cada país miembro a cumplir con sus obligaciones, pero no va acompañada realmente del principio de solidaridad regional en el reparto de las cargas. No obstante, la CICAD ha establecido una unidad de desarrollo alternativo que ejecuta y coordina programas en zonas de cultivos. Estos programas son financiados por la comunidad internacional de donantes y se realizan con los gobiernos de los Estados miembros, dando prioridad a la cooperación horizontal a través de mecanismos de consulta, coordinación y acción conjunta, pero su incidencia es también muy limitada.

En el campo del lavado de activos se han realizado avances en términos de leyes y reglamentos pero el punto débil sigue estando en la aplicación. 33 países del hemisferio han firmado la Convención Interamericana contra la corrupción y la mayoría la han tipificado como delito, pero la información que se dispone sobre la aplicación de la legislación es mínima. Lo mismo ocurre con la cooperación judicial y la extradición. El informe 2003-2004 introdujo por primera vez indicadores sobre el crimen organizado transnacional, pero la información no permitió un diagnóstico sobre la forma de operar de las redes, lo cual se considera imprescindible para avanzar hacia una estrategia hemisférica en ese terreno ${ }^{17}$.

Los mecanismos de control de la CICAD están en permanente revisión; tras la remodelación en 2006 de la estructura institucional de la OEA, la CICAD se dividió en 7 secciones; además de la secretaria ejecutiva, el MEM, Anti-lavado de activos, Reducción de la demanda, Desarrollo educacional e investigación, Reducción de la Oferta y Desarrollo Alternativo. Debido a los problemas de financiamiento del fondo regular de la OEA, el Secretario General propuso la creación de un mecanismo financiero a través de la asignación de un pequeño porcentaje de los activos incautados al narcotráfico y lavado de activos para destinarlo a financiar las actividades

16 El Fondo de Solidaridad es un fondo establecido, mantenido y controlado por la Secretaría Ejecutiva de la CICAD que se financia con donaciones.

17 Esta cuestión se discutió en la reunión de expertos organizada por la CICAD en Bogotá el 18 de noviembre de 2005

En el lavado de activos se ha avanzado en términos de leyes y reglamentos pero el punto débil sigue estando en la aplicación. Lo mismo ocurre con la cooperación judicial y la extradición 
relacionadas con la capacitación y fortalecimiento institucional de las administraciones nacionales. Para la CICAD el fortalecimiento de las comisiones nacionales es fundamental porque sobre ellas recae el peso de la aplicación de la estrategia.

El último informe hemisférico de 2015 correspondiente a la sexta ronda de evaluación del MEM se basó en las recomendaciones estándar emanadas del Plan de Acción 2011-2015 de la Estrategia Hemisférica sobre Drogas aprobados ambos en 2010 ${ }^{18}$. El informe concluye que "el mayor nivel de cumplimiento total se encontró en el área de Medidas de Control, con 52\%, seguido por un 47\% en el área de Cooperación Internacional, así como 45\% y 39\% en las áreas de Fortalecimiento Institucional y Reducción de la Demanda, respectivamente. El área de Reducción de la Oferta cuenta con un 62\% de las recomendaciones cumplidas, tomando en consideración sólo los países que cuentan con cultivos ilícitos de relevancia” (CICAD, 2015). En el área de Fortalecimiento Institucional, el informe concluye que la mayoría de los países cuentan con autoridades nacionales de drogas que coordinan las políticas nacionales de drogas con datos recientes y, salvo cinco, disponen de observatorios de drogas.

En cambio, en la Reducción de la Demanda, aunque según el informe señala que la mayor parte de países cuentan con planes y programas, la mayoría no han realizado monitoreo y evaluación de los resultados y sólo algunos cuentan con programas de prevención del consumo de drogas. 16 países del hemisferio (47\%) no tienen un sistema de programas de prevención dirigido específicamente a los distintos grupos poblacionales. Aunque ha habido progreso en relación con la atención de la demanda de drogas desde una perspectiva de salud pública, se señala que sería preciso aumentar los centros de tratamiento y mejorar el seguimiento y evaluación de los programas de reducción de la demanda de drogas en general.

En el área de Reducción de la Oferta, todos los países implementan medidas de erradicación de cultivos ilícitos, pero casi la mitad de los países no promueven la realización de investigaciones para determinar el impacto ambiental ocasionado por la producción ilícita de drogas. El informe señala también que, de los nueve países que mayor coca producen, solo dos promueven políticas y programas de desarrollo alternativo, integral y sostenible que favorecen la inclusión social y la reducción de la pobreza, uno cumplió solo parcialmente, tres no cumplieron y a otros tres no les era aplicable la meta.

En el área de Medidas de Control, la totalidad de los Estados cuentan con una Unidad de Inteligencia Financiera, conforme a las exigencias internacionales y casi la totalidad de los Estados miembros cuentan con mecanismos formales o informales de intercambio de información de inteligencia entre las agencias responsables del control del tráfico ilícito de drogas y delitos conexos. Sin embargo, el informe detecta grandes carencias en la investigación sobre el impacto ambiental ocasionado por la producción ilícita de drogas. En el área de Cooperación Internacional, el informe constata que todos los países cuentan con instrumentos jurídicos para el decomiso del producto derivado del tráfico ilícito de drogas y disposiciones legales para la extradición por lavado de activos y que permiten brindar asistencia judicial recíproca a terceros Estados. Sin embargo, algunos Estados no cuentan con disposiciones legales que permitan la extradición por tráfico ilícito de drogas.

18 Adoptada por la CICAD en su cuadragésimo séptimo período ordinario de sesiones Aprobado el 3 de Mayo de 2010 Washington, http://www2.juridicas.unam.mx/marihuana-caso-mexico/wp-content/uploads/2016/02/ Estrategia_drogas-2011-2015.pdf

\section{Para la CICAD el fortalecimiento de las comisiones nacionales es fundamental porque sobre ellas recae el peso de la aplicación de la estrategia}


Hasta hoy la OEA se ha limitado al control de la aplicación de la normativa internacional vigente, la elaboración de criterios y códigos de conducta para la armonización de políticas, y la cooperación técnica para ayudar a los gobiernos a aplicar los compromisos existentes. No se ha planteado el cuestionamiento del modelo actual, que pone el énfasis en las medidas de erradicación, interdicción y represión ni se ha hecho una evaluación sobre los resultados obtenidos que vaya más allá de los criterios cuantitativos del MEM. Tampoco se examinan los enfoques subregionales de lucha contra el narcotráfico, por lo que no se puede hablar de complementariedad. Sin embargo, debido a la influencia de los Estados Unidos y de su acción en la lucha contra el narcotráfico, no se puede subestimar su influencia en el diseño de las políticas regionales.

\subsection{La estrategia andina sobre el problema mundial de las drogas}

La preocupación por los temas del narcotráfico en los países andinos se inició antes de que la OEA aprobara el Plan de Acción de Río de 1986 y de la firma del Convenio de Viena de Naciones Unidas de 1988. El 14 de diciembre de 1985, los países miembros del entonces Pacto Andino aprobaron la decisión 98/V en la que se calificaba al narcotráfico como delito contra la Humanidad $^{19}$. Esta decisión fue coetánea del inicio de la campaña de Guerra contra la droga impulsada por la Administración de Ronald Reagan, en la que el narcotráfico comenzó a considerarse como una amenaza contra la Seguridad nacional (Camacho, 2006). Un año más tarde se firmó el "Convenio Rodrigo Lara Bonilla”20 y en agosto de 1989 los países miembros se comprometieron a elaborar un Plan de acción destinado a eliminar los cultivos ilegales de coca y potenciar el desarrollo alternativo para los habitantes de las zonas productoras ${ }^{21}$. Ese mismo año la declaración de Galápagos sobre el "Compromiso andino de Paz, Seguridad y Cooperación”22, partiendo del principio de responsabilidad compartida, proponía establecer procedimientos prácticos de colaboración para coordinar la lucha contra el terrorismo y el narcotráfico, con lo que se establecía una vinculación entre ambos fenómenos delictivos. Pero también contemplaba concertar acciones subregionales impulsando la sustitución de cultivos ilícitos en el marco de programas de desarrollo rural. Para poder abordar este último se propuso obtener recursos financieros de la comunidad de donantes.

En julio de 1990, la Declaración andina sobre la lucha contra el narcotráfico reconocía la dimensión política, económica y social del problema y la necesidad de establecer los medios y recursos necesarios para el desarrollo alternativo y la sustitución de cultivos, así como para apoyar las balanzas de pagos, mitigar el impacto social de la lucha contra el tráfico ilícito de drogas y estimular las exportaciones ${ }^{23}$ y las inversiones extranjeras, al tiempo que se acordaron

19 Previamente, en agosto de 1984, Bolivia, Colombia, Ecuador, Panamá, Venezuela, Nicaragua y Perú habían aprobado la Declaración de Quito sobre Tráfico de drogas en la que ya se definía al tráfico de drogas como un Delito contra la Humanidad.

20 Convenio entre los países miembros del Acuerdo de Cartagena sobre cooperación para la prevención, el uso indebido y la represión del tráfico ilícito de estupefacientes y sustancia psicotrópicas de 30 abril de 1986.

21 Decisión 250 "Plan de acción para la sustitución y desarrollo alternativo en las zonas productoras de coca de los países andinos" de 11 agosto de 1989, en Lima.

22 Reunión de Galápagos de 17 y 18 de diciembre de 1989.

23 Se hacía mención expresa a la "Iniciativa Comercial Andina" ofrecida por los Estados Unidos, que acabaría dando lugar al ATPA, Régimen de Preferencias para los Países Andinos, sustituida posteriormente por el ATPDEA que terminó en 2011.
En 1985, los países miembros del entonces Pacto Andino aprobaron la decisión 98/ $\mathrm{V}$ en la que se calificaba al narcotráfico como delito contra la Humanidad 
acciones policiales y de represión contra el narcotráfico. En noviembre de 1990 se creó el Grupo de consulta y coordinación permanente de lucha contra el tráfico ilícito de estupefacientes y sustancias psicotrópicas y el Acta de Barahona de 1991, estableció el Centro Regional Andino de Coordinación e Información para la lucha contra el narcotráfico.

La declaración de Barahona destacaba la necesidad de programas de desarrollo alternativo dirigidos a los campesinos. Sin embargo, al mismo tiempo se produjo una militarización de la represión, no sólo contra el narcotráfico tráfico y otras actividades delictivas, sino también con campañas de erradicación forzosa que implicaron el uso del ejército contra los campesinos, especialmente en Bolivia, Perú y, sobre todo, Colombia. Así dicha presión llevó al gobierno de Alejandro Toledo en Perú a cambiar su política de negociación con los campesinos cultivadores de coca para cumplir con los objetivos estadounidenses y al gobierno de Sánchez de Lozada en Bolivia a desistir de la negociación con los cocaleros (Youngers \& Rossin, 2004). Lo mismo ocurrió con el acuerdo antinarcóticos entre Estados Unidos y Ecuador de 2005, por el que este país se comprometía a incrementar un $12 \%$ los arrestos por cargos sobre drogas y condujo al incremento de las detenciones y la encarcelación de pequeños delincuentes intermediarios a penas mayores que los homicidas (Camacho, 2006).

En septiembre de 1995 se creó un Grupo de alto nivel sobre drogas para emprender acciones conjuntas en el seno de la Comunidad Andina (CAN) que sucedió al Pacto Andino. Bajo el principio de responsabilidad compartida y a partir de un enfoque multilateral, se pretendía promover la cooperación internacional y, en particular, el desarrollo alternativo como incentivo al abandono de los cultivos de hoja de coca. Pero aún se estaba muy lejos de un planteamiento común ya que las políticas nacionales continuaron siendo divergentes.

El Acta de Carabobo de junio de $2001^{24}$ otorgó una atención prioritaria a la aplicación del Plan Andino de cooperación para la lucha contra las drogas ilícitas y delitos conexos aprobados días antes por la Decisión 505 del Consejo Andino de Ministros de Relaciones Externas ${ }^{25}$. Los Presidentes andinos destacaron que los esfuerzos para la lucha contra las actividades ilícitas habían de ir acompañados de los recursos financieros necesarios para el desarrollo y se hacía una llamada a la Comunidad Internacional y especialmente a los Estados Unidos y la UE para mejorar los tratamientos preferentes de acceso a los mercados. Esas medidas se establecieron tanto en los Estados Unidos, como la $\mathrm{UE}^{26}$ con efectos positivos en las exportaciones andinas, aunque los beneficios no se repartieron de forma equilibrada entre los diferentes países miembros. La resolución de la OMC de 2005 contraria al mantenimiento del SPG Drogas de la UE ${ }^{27}$ y la apuesta por una generalización de los acuerdos para establecer ZLC regionales y bilaterales tanto por parte europea como estadounidense supusieron el fin de los tratamientos preferenciales para productos de desarrollo alternativo.

24 XIII Consejo Presidencial Andino de 23 y 24 de junio de 2001.

25 http://www.sice.oas.org/trade/junac/decisiones/dec505s.asp

26 En 1991 la Comunidad Europea creó temporalmente un régimen especial dentro de su Sistema de Preferencias Generalizadas (SPG) para los países en desarrollo que incrementaba las preferencias a los países andinos entre otros por su contribución a la lucha contra la producción y el tráfico de drogas.

27 Fue suprimido en 2005 a consecuencia de una decisión contraria a su mantenimiento del Órgano de Solución de Controversias de la Organización Mundial del Comercio debido a su carácter discriminatorio respecto a otros países con circunstancias similares.

\section{Bajo el principio de responsabilidad compartida y un enfoque multilateral se promovía la cooperación internacional y el desarrollo alternativo como incentivo al abandono de los cultivos de coca}


El Plan Andino contenido en la decisión 505 partía de la naturaleza compartida del problema de la lucha contra las drogas ilícitas, lo que teóricamente conlleva de forma inherente la cooperación internacional, tanto en el plano subregional andino, como sudamericano, hemisférico y mundial. Incorporaba el elemento de solidaridad con el reconocimiento de que "los esfuerzos nacionales y subregionales en la lucha contra las drogas ilícitas deben ir acompañados por la cooperación internacional”, pero como en otras ocasiones no se especificaban las vías de financiación efectiva. El primer Programa de Acción, recogido en la misma decisión 505, precisó los objetivos y principios en tres niveles: el fortalecimiento de las estrategias nacionales; el refuerzo de las estrategias binacionales; y la estrategia comunitaria. Esta última estaba basada en la coordinación entre las autoridades nacionales, la armonización de legislaciones y la concertación en foros internacionales en el marco de la PEC. Se contemplaba intercambios de información entre servicios de inteligencia, autoridades nacionales y cuerpos de policía, formación conjunta de funcionarios, acuerdos de asistencia judicial, armonización de legislaciones, intercambio de experiencias, represión del tráfico ilícito actualizando los instrumentos convencionales. La creación como órgano ejecutivo del Comité Andino de Desarrollo Alternativo (CADA) prevista en la Decisión 505 no se produjo hasta junio de 2003 con la Decisión 549.

El 12 de marzo de 2003 se aprobó en Bogotá el Compromiso para el Fortalecimiento de la Coordinación en la Lucha contra el Terrorismo y el Problema Mundial de las Drogas y los Delitos Conexos, una declaración en la que, junto a los países andinos, participaron Brasil y Panamá. Con esta asociación de narcotráfico y terrorismo internacional, este compromiso parecía alinearse más con las tesis del Plan Colombia, financiado por los Estados Unidos, poniendo el énfasis del problema en los grupos delictivos y la neutralización de la oferta. En consecuencia, las áreas prioritarias fueron: el tráfico ilícito de armas y explosivos, el desvío de precursores químicos, el control de finanzas, el desarrollo legislativo, el control de fronteras y la cooperación en materia de inteligencia. En contraste, no se mencionaban ni las acciones de desarrollo alternativo, ni la reducción de la demanda.

No obstante, en febrero de 2004 un documento titulado "El Desarrollo Alternativo Sustentable y Preventivo: una visión Conjunta del CADA” expresaba las expectativas de abrir una nueva fase en que los principios del primer plan de acción diesen paso a una mayor concreción de los compromisos y se instaba a que la comunidad internacional "asuma con hechos los compromisos que implica el principio de responsabilidad compartida”. En junio de 2004 se acordó que el proyecto piloto de Sistema de Información de Desarrollo Alternativo para la Región Andina (SIDARA), creado previamente entre Colombia y Perú, se extendiera al plano regional como mecanismo de intercambio de experiencias y de difusión de las políticas y programas de desarrollo alternativo en los países de la CAN.

En junio de 2005, se adoptó el contenido de la primera "Estrategia Andina de Desarrollo Alternativo, Integral y Sostenible”28 adoptada para 5 años para contribuir a la reducción de la pobreza y a la cohesión social estableciendo metas e indicadores que orienten las políticas nacionales y comunitarias. Según los principios enunciados, la estrategia estaba vinculada a la pacificación y la estabilización de las áreas de intervención. Al mismo tiempo, se establecía que la estrategia de desarrollo alternativo sería ejecutada en el marco de las estrategias integrales de lucha

\section{El primer Programa de Acción precisó los objetivos y principios en tres niveles: el fortalecimiento de las estrategias nacionales, el refuerzo de las estrategias binacionales y la estrategia comunitaria}


contra las drogas ilícitas y por tanto asociada a los esfuerzos de erradicación y a las garantías del imperio de la ley.

Cuando se aprobó esa estrategia andina, cada país miembro de la CAN tenía su propio plan de desarrollo alternativo, con sus prioridades y diferentes enfoques. Por su parte, los gobiernos y organizaciones locales tuvieron una participación muy limitada en la planificación de los programas y la escala de los proyectos no fue suficiente para transformar las economías locales por falta de articulación con los objetivos de la política nacional y con las políticas sectoriales en materia ambiental, salud, educación, saneamiento básico y desarrollo productivo y rural (Ayuso \& Beltrán, 2007). La estrategia proponía un nuevo modelo con enfoque integral y sostenible, pero no se establecieron instrumentos financieros, ni cuáles serían los órganos de ejecución de las políticas comunes de alcance regional. En la práctica, eso suponía que la puesta en marcha de la estrategia dependiera de los recursos foráneos y por tanto condicionada por actores extraregionales. Esto distorsionaba las políticas nacionales, especialmente cuando, como ocurría con las aportaciones de los Estados Unidos a Colombia, se premiaban más las alianzas a su política de seguridad regional que la efectividad de las políticas. A lo que se sumaba el mecanismo de desertificación unilateral, que supone una reducción de financiación si Estados Unidos entiende que un Estado no está cumpliendo con los compromisos de disminución de la oferta.

Para la implementación de las mencionadas decisión 505 y la 614 además de la Decisión 602 "Norma andina para el control de sustancias químicas que se utilizan en la fabricación ilícita de estupefacientes y sustancias psicotrópicas" de diciembre de $2004^{29}$ la CAN contó con financiación de la UE, fundamentalmente los programa PRADICAN I y PRADICAN II además de proyectos como el PRELAC y, más tarde, el de la Ruta de la Cocaína que se analizan posteriormente. Además se hicieron Proyectos de desarrollo alternativo en Bolivia y Perú y los programas denominados "Laboratorios de Paz" en Colombia o de reducción de la demanda en el Perú. Uno de los principales resultados fue la creación del Sistema Andino de Información sobre Drogas (SAID) con la armonización de 22 indicadores que permitirán tener datos estandarizados comparables.

Sin embargo, las estrategias y planes de desarrollo alternativo beneficiaron, sobre todo de los grupos sociales de base afectados más organizados, olvidando a los sectores más marginados (International Crisis Group, 2005). Son problemas derivados de la focalización de los programas de desarrollo alternativo que crearon desequilibrios con otras áreas y generan tensiones sociales a la vez que favorecieron el desplazamiento de los cultivos ilícitos y por ende de la criminalidad asociada al narcotráfico. El carácter transversal de las estrategias de desarrollo alternativo respecto a otras políticas de cooperación regional haría necesario una mayor articulación de las diversas estrategias e introducir mecanismos operativos de coherencia y complementariedad con las otras políticas de cooperación regional: Desarrollo Sostenible, Agenda Social, Política de Integración y Desarrollo fronterizo, Seguridad y Medidas de Confianza. La conjugación de objetivos muy ambiciosos, junto a la falta de concreción de obligaciones jurídicas y la dependencia de los recursos externos, en su mayoría condicionados, ha sido una constante de los proyectos de desarrollo alternativo.

Más de 10 años después de adoptarse la Decisión 505 la sexta reunión de expertos gubernamentales para la Actualización de la normativa andina sobre drogas ilícitas de octubre de 2012

29 http://www.sice.oas.org/trade/junac/Decisiones/dec602s.asp 
propuso una nueva "Estrategia Andina sobre el problema mundial de las Drogas 2012-2019"30 que trataba de unificar la normativa existente y, actualizarla y simplificarla. Esta estrategia se complementará con dos planes de Acción 2012-2016 y 2016-2019. La estrategia se basa en unos lineamientos específicos: reducción de oferta y medidas de control; control del lavado de activos; reducción de la demanda; desarrollo alternativo integral y sostenible, incluido el desarrollo alternativo preventivo; investigación y formación; y fortalecimiento institucional. Este último comprende el apoyo a los Observatorios Nacionales de Drogas, el intercambio de información entre autoridades y promover la definición de metodologías estandarizadas para fortalecer y actualizar las estrategias nacionales. El Plan de acción 2012-2016 establece unos objetivos y pretende establecer un Programa andino con las líneas prioritarias estableciendo unas metas y resultados esperados susceptibles de verificación. No obstante, corresponde a cada estado la concreción de las políticas y tampoco existe un presupuesto específico destinado a la acción comunitaria que dependerá de nuevo de la financiación exterior. El declive de la Comunidad Andina como organismo de integración regional que se inició con la salida de Venezuela en el 2006 sumado a las divergencias entre Colombia y Perú, por una parte, y Bolivia y Ecuador, por otra en sus relaciones con Estados Unidos y la UE ha debilitado la cooperación andina, aunque no se ha interrumpido y prosigue a través de otros mecanismos subregionales e inter-regionales.

\section{La Estrategia Suramericana en el marco de UnASUR}

En los últimos años se han desarrollado nuevas iniciativas regionales que incorporan las cuestiones de seguridad en ALC y tendrán un impacto en el contenido del diálogo y la cooperación interregional. Entre éstas destacan la creación en 2008 del Consejo Sudamericano de Defensa y del Consejo Suramericano sobre el problema mundial de la Droga ${ }^{31}$ (CSPMD) en mayo de 2010 en el marco de la UNASUR (Unión de Naciones Suramericanas). Este último propone el desarrollo de una identidad sudamericana para hacer frente a este problema y elaborar una posición común en los foros internacionales. Este foro fue presentado formalmente a la Reunión de Alto Nivel de la UE del mecanismo de coordinación y cooperación entre la reunión de la CELAC UE en Bruselas en marzo de 2012. En noviembre de 2012, se creó además el Consejo de América del Sur en materia de seguridad ciudadana, justicia y contra la delincuencia transnacional organizada. Este Consejo debe coordinar sus tareas con el CSPMD. Además de promover la coordinación de las políticas de seguridad ciudadana entre los Estados miembros, el objetivo de estos Consejos es mejorar las capacidades para llevar a cabo los compromisos internacionales.

El CSPMD pretende proponer estrategias, planes y mecanismos de coordinación y cooperación entre los Estados miembros para incidir de forma integral en todos los ámbitos de la problemática. Uno de los instrumentos es la creación de la "Red de Observatorio de drogas de los estados miembros de la Unión de Naciones Suramericanas”, aprobado en julio de 2014 mediante la cual se quiere realizar un informe sobre el "Estado de situación del consumo de drogas y caracterización de las nuevas ofertas de las drogas ilícitas en UNASUR”. También

30 SG/dt 473 de 12 de diciembre de 2012. Propuesta técnica consensuada en la VI Reunión de Expertos Gubernamentales para la actualización de la normativa andina sobre drogas ilícitas, Quito - Ecuador, 10 y 11 de octubre de 2012.

31 http://www.unasursg.org/es/node/30
Se propuso una nueva "Estrategia Andina sobre el problema mundial de las Drogas 2012$2019^{\prime \prime}$ que trataba de unificar la nomativa existente, actualizarla y simplificarla 
se acordó la creación de un Centro de Estudios Suramericanos en Materia de Drogas. Para construir una identidad suramericana para enfrentar el problema mundial de las drogas, el CSPMD acordó en 2015 un documento común en su sesión del 31 de agosto en Montevideo. Esta posición fue la que se presentó en nombre de UNASUR en el marco de la UNGASS de 2016. En este documento se defendían de nuevo los principios de responsabilidad común y compartida; enfoque integral, equilibrado, multidisciplinario y sostenible, el enfoque transversal de los DDHH, la abolición de la pena de muerte por delitos relacionados con las drogas, la proporcionalidad de las penas, la sustitución de los cultivos con participación social y la presencia del Estado en base a la legislación local, así como mecanismos de lucha contra el narcotráfico y el crimen organizado ${ }^{32}$.

En este sentido, este documento trataba de reforzar una posición revisionista de la estrategia internacional sobre las drogas que superara el esquema punitivo. Sin embargo, en la práctica las políticas que aplican cada uno de los países y las posiciones que se mantuvieron en la UNGASS 2016 no fueron tan unánimes y por ello su influencia quedó diluida ante las posturas más inflexibles que mantuvieron otros países como Rusia o China o reticentes como Estados Unidos (Tokatlian y Comini, 2016). El CSPMD ha abierto un proceso para la reflexión y la cooperación regional, pero aún dista de ofrecer una capacidad operativa. En realidad esta cooperación de carácter político convive con las iniciativas de la CAN ya mencionadas, pero también de MERCOSUR. De hecho, la XX Reunión Especializada de Autoridades de Políticas en Materia de Drogas de MERCOSUR (organismo creado en 1998), que se llevó a cabo en Brasil el 14 de mayo de 2015 ya adoptó una resolución sobre la UNGASS 2016 que iba en una línea similar a la del CSPMD ${ }^{33}$.

La declaración de Brasilia, mucho más escueta que la del CSPMD, también apostó por una posición revisionista aunque bastante moderada, poniendo énfasis en la importancia de que "todos los enfoques, incluyendo los nuevos métodos, estén basados en la evidencia científica" y contribuyan al fortalecimiento de las diversas estrategias nacionales para lograr una mayor efectividad ante los retos globales y los nuevos retos que han surgido. Dentro de MERCOSUR también conviven posiciones más aperturistas como Uruguay, que ha despenalizado algunos usos del cannabis y ha introducido un mercado regulado pionero en la región, y otros más reacios como Brasil, que enfrenta una mayor presión de las rutas del narcotráfico. En lo que sí hay un acuerdo generalizado es en la necesidad de incluir la protección de los derechos humanos en todas las dimensiones para enfrentar el problema y descriminalizar la adicción, incorporando las políticas de reducción de daños, aunque la situación efectiva en cada país es diversa. En cambio en la Declaración de Brasilia no se hizo referencia al desarrollo alternativo, ya que no son países productores, al menos en la dimensión que se da en los países andinos.

La heterogeneidad de situaciones que se da en la región también se puso de manifiesto en la VI Conferencia Latinoamericana y I Caribeña sobre Políticas de Drogas que se celebró en Santo Domingo, Rep. Dominicana, el 5 de octubre de 2016. En los debates se puso de manifiesto que, si bien hay un cierto consenso del fracaso del sistema imperante, aún no hay acuerdo sobre qué cambios de calado deben hacerse en el sistema internacional. En este sentido la UNGASS 2016 se percibió como una "oportunidad perdida" como la calificó la Comisión Global sobre

\section{En la práctica las políticas que aplican cada uno de los países y las posiciones que se mantuvieron en la UnGASS 2016 no fueron tan unánimes}

\footnotetext{
32 https://www.unodc.org/documents/ungass2016/Contributions/IGO/UNASUR/UNASUR_common_position_on_ UNGASS_spanish.pdf (última visita 10/10 2016)

33 https://medios.presidencia.gub.uy/tav_portal/2015/noticias/NO_P934/Declaraci\%C3\%B3n-Mercosur.pdf
} 
$\operatorname{Drogas}^{34}$. No obstante se valoró la importancia de la participación de la sociedad civil en todo el proceso de debate y se propuso continuar la labor para preparar la Reunión de Alto nivel de Naciones Unidas que se prevé para 2019.

\section{La Cooperación interregional entre la UE y ALC}

Las acciones de las instituciones europeas para combatir el fenómeno de la droga datan de finales de la década de los ochenta, aunque inicialmente se limitaban a la coordinación de las políticas antidrogas de los Estados miembros. Una de las primeras veces en que se menciona la cooperación comunitaria con los países productores fue la Recomendación de Decisión del Consejo relativa a la participación de la Comunidad en los trabajos preparatorios y en la Conferencia internacional sobre el abuso y el tráfico ilícito de drogas, COM (86) 457 final, de 5 de agosto de 1986. Es en los años noventa, a partir de la entrada en vigor del Tratado de la Unión Europea de Maastricht de 1992 y su posterior revisión en Ámsterdam en 1997 cuando la acción internacional contra las drogas empieza a generalizarse (Pi, 2007). La política de la UE se articuló a través de estrategias plurianuales, acompañadas de sus correspondientes Planes de Acción que se han ido renovando regularmente tras hacer una evaluación de su desempeño. La actual estrategia para el período 2013-2020 fue aprobada por el Consejo Europeo de 7 de diciembre de 2012 y fue acompañada del Plan 2013-2016 de 6 junio de 2013. En ambos documentos, como en estrategias anteriores, la UE asumió el principio de responsabilidad compartida entre países productores y países consumidores y la necesidad de un tratamiento equilibrado entre reducción de la demanda y combate a la oferta, en la línea de lo que establecen los instrumentos de Naciones Unidas. La cooperación con ALC en este ámbito ha combinado el diálogo político, la concesión de ventajas comerciales y la cooperación al desarrollo.

Las primeras acciones de cooperación de la UE se centraron en los países andinos y se remontan a los años 90. Una de las primeras fue precisamente un Plan Trienal (1990-1993) para Colombia en la que se incluían proyectos de desarrollo alternativo al cultivo de la coca y proyectos de cooperación no específicamente ligados a las drogas. La importancia del tema en las relaciones con esta región dio lugar al nacimiento del Diálogo Especializado de Alto Nivel sobre Drogas UE-CAN que se inició en Bruselas en 1995 y funciona a base de reuniones periódicas. Posteriormente se constituyó el Diálogo conjunto UE-AL en materia de droga cuya primera Reunión de Alto Nivel fue en marzo de 1998. El Plan de Acción Global sobre Drogas para la UE-ALC se adoptó en la I Cumbre UE ALC celebrada en Río de Janeiro en 1999, donde se estableció la Asociación estratégica biregional y se creó el Mecanismo de Coordinación y Cooperación en materia de Drogas entre la UE y ALC. Éste incorporó los Planes de Acción de Barbados y Panamá, de 1999 y fue desarrollado por las Prioridades de Lisboa adoptadas en el año 2000 que incluía, reducción de la demanda, desarrollo alternativo, lavado de activos y cooperación marítima.

Este mecanismo de diálogo además de permitir concretar la cooperación debía servir para acercar las estrategias hacia una postura compartida que equilibrase las políticas de reducción de la oferta y de la reducción de la demanda (Armenta, Jelsma y Metal, 2006). Además de reiterar el principio de responsabilidad compartida, en el diálogo se insistía en un enfoque integrado,

\section{La UE asumió} el principio de responsabilidad compartida y la necesidad de un tratamiento equilibrado entre reducción de la demanda y combate a la oferta

34 La Comisión Global sobre drogas está formada por un grupo de personalidades, incluidos varios expresidentes, que defienden la reforma del actual sistema internacional de regulación de las drogas. http://www. globalcommissionondrugs.org/es/ 
equilibrado y participativo, el desarrollo sostenible, la conformidad con el derecho internacional y el pleno respeto a la soberanía y la integridad territorial de los Estados y el conjunto de derechos fundamentales y libertades fundamentales. Dichos principios han sido recogidos e incorporados en las estrategias de lucha contra la droga de la Unión Europea. En este sentido, la UE reconocía su responsabilidad a nivel mundial, no sólo como consumidora de todo tipo de drogas, sino también como productora y exportadora de drogas sintéticas.

Los diálogos han servido también para marcar unos objetivos generales y unas áreas de acción que luego deben hacerse efectivas mediante proyectos o instrumentos concretos. Se ha insistido en la necesidad de enmarcar la lucha contra la droga dentro de un contexto más amplio de políticas de desarrollo. Sin embargo, uno de los principales obstáculos para conseguir estrategias consensuadas ha sido la política anti-droga patrocinada por los Estados Unidos en la zona. La UE no comparte algunas de las premisas de dicha política (Labrousse, 2007), sin embargo, no ha conseguido adoptar una acción estratégica de carácter regional que le permita ejercer un papel influyente a escala global.

Uno de los conceptos clave que ha guiado la política de cooperación comunitaria en este ámbito, en cooperación con la ONU, ha sido el desarrollo alternativo como eje para la política de reducción de la oferta. Entre los donantes a nivel mundial, la UE es quien más claramente ha apostado por este enfoque: la posición que ha mantenido es que el problema de cultivos ilícitos se resuelve únicamente mediante una estrategia global que atienda a las causas estructurales, es decir la pobreza y la marginación rural (Bataller, 2000). De ahí el énfasis en propiciar un desarrollo que pueda ser una alternativa real al cultivo de droga. Pero para que dichas alternativas sean viables deben situarse en un contexto amplio de desarrollo, que incluye múltiples factores, como la promoción del empleo y de actividades económicas alternativas, las estructuras de transporte y de comunicación, la transferencia de tecnología, el desarrollo de las instituciones y de las comunidades locales, el fortalecimiento de las instituciones judiciales, los servicios sociales o la protección de los derechos humanos, entre otras (Pi, 2007).

Esta aproximación está ligada al mencionado principio de responsabilidad compartida. La UE defiende el multilateralismo, y ello se traduce en una potenciación de programas regionales de lucha contra la droga. Sin embargo, a pesar de algunas iniciativas interesantes, no se ha podido explotar a fondo las posibilidades del desarrollo alternativo ya que para ello se necesita, no sólo más recursos de los destinados, sino también un liderazgo y compromiso del país afectado. En el marco de las políticas de cooperación al desarrollo sería necesaria también una acción mucho más coordinada entre la UE y sus Estados miembros. De esta manera, durante décadas la UE dejó el liderazgo de la lucha contra la droga en la región a los Estados Unidos, que ha primado el enfoque securitario.

Esto ha afectado también a la agenda de seguridad interregional entre la UE y ALC. La cooperación en la lucha contra el tráfico de drogas entre la UE y ALC ha desarrollado diversos instrumentos de cooperación interregional para hacer frente al creciente incremento de la violencia en la región. La lucha contra los carteles colombianos patrocinada por Estados Unidos en los años ochenta tuvo como consecuencia difundir el crimen organizado a lo largo de América Central y México como un corredor para el mercado de América del Norte. El crecimiento del tráfico de drogas y armas en esa región ha tenido un impacto negativo sobre el estado de la seguridad regional (Bagley, 2012). Las drogas procedentes de Colombia y Bolivia viajan a través de Perú y Venezuela a Europa a través de las Azores, Cabo Verde y Canarias. Pero también atra-
Uno de los conceptos clave que ha guiado la política de cooperación comunitaria ha sido el Desarrollo alternativo como eje para la política de reducción de la oferta 
viesan Brasil y otros países de la costa de América del Sur a África Occidental hacia Europa y más allá convirtiéndolo en un problema de carácter transnacional que precisa de instrumentos y cooperación internacionales (Ayuso \& Viilup, 2014).

En la Cumbre UE-ALC de Madrid en 2002 se ampliaron los temas de seguridad incluyendo la condena del terrorismo, la lucha contra el crimen organizado y el tráfico de drogas y las referencias al conflicto colombiano y la crisis en Haití. Más adelante, el 5 y 6 de marzo de 2008 se llevó a cabo en Lima la Conferencia Internacional "Una Agenda Latinoamericana de Cooperación de Seguridad con la Unión Europea”. El Protocolo de Lima instó a los gobiernos a cooperar para estructurar los sistemas de seguridad como parte de la protección de los Derechos Humanos y de los bienes públicos. Asimismo, instó a fomentar la participación de la sociedad civil para integrar los derechos humanos y promover el papel de los parlamentos en el control y supervisión de los sectores de seguridad y defensa. Por entonces, la Asamblea Parlamentaria Euro-Latinoamericana (EuroLat) ya se había incorporado a los debates sobre la agenda de seguridad con un enfoque más integral del cual surgió la Carta Euro-Latinoamericana para la Paz y seguridad ${ }^{35}$ que se aprobó en 2009.

La Carta trataba de dar coherencia a las acciones de cooperación en materia de seguridad, incluidos los aspectos relacionados con la seguridad pública, la seguridad del Estado y la seguridad regional en tanto conceptuales como materiales (Ayuso, 2014). Por ello incluyó una serie de capítulos en los que se instaba a una lucha conjunta contra el terrorismo, el narcotráfico, el tráfico de armas, el lavado de dinero y, en general, el crimen organizado. Pero también incluyó la necesidad de acciones en favor de la sostenibilidad social y medio-ambiental. A pesar de su naturaleza política y no normativa, este documento pretendía dar visibilidad y coherencia a un sector de la relación birregional que ha tenido una proyección fragmentada en la agenda. Sin embargo, en la práctica no se avanzó mucho en la coordinación de las estrategias existentes de seguridad regional, con los otros instrumentos e instituciones regionales y birregionales existentes. La UE ha desarrollado, por una parte proyectos destinados al control de las sustancias y el tráfico y por otra ha establecido algunos proyectos de cooperación internacional para el desarrollo alternativo focalizados sobre todo, como se ha mencionado, en la zona andina.

En el ámbito del control de sustancias, entre 2004 y 2006, la CAN, con recursos de la UE y el apoyo de la Oficina en Colombia del Programa de las Naciones Unidas para el Desarrollo (PNUD), ejecutó el proyecto PRECAN que contribuyó al desarrollo e implementación de políticas nacionales para el control y fiscalización de sustancias químicas precursoras y permitió la aplicación de la "Norma andina para el control de sustancias químicas que se utilizan en la fabricación ilícita de estupefacientes y sustancias psicotrópicas”(Decisión 602). Ello permitió la capacitación de profesionales (de salud, educación, policías, jueces y funcionarios de aduanas) y el intercambio de experiencias. Posteriormente la experiencia se extendió al conjunto de la región con el proyecto "Prevención del desvío de precursores de drogas en la región de América Latina y el Caribe" (PRELAC) creado en 2009 y desarrollado en colaboración con la Oficina de las Naciones Unidas contra la Droga y el Delito (ONUDD) hasta 2016 $6^{36}$ Entre 2007 y 2010 se desarrolló el proyecto DROSICAN sobre drogas sintéticas, que contemplaba tanto la

\section{La Carta trataba} de dar coherencia a las acciones en materia de seguridad, incluidos los aspectos relacionados con la seguridad pública, la seguridad del Estado y la seguridad regional

35 https://www.parlamentomercosur.org/innovaportal/v/4707/1/parlasur/carta-euro-latinoamericana-para-la-paz-y-laseguridad.html

36 El proyecto PRELAC terminó en febrero 2016, después de siete anos de asistencia sin interrupciones a 17 países de América Latina y el Caribe. 
prevención del consumo como el reforzamiento de los observatorios nacionales de drogas para la estandarización y homologación de la información.

Las experiencias acumuladas en dichos programas ALC y la constatación de que las redes de narcotráfico están cada vez más transnacionalizadas en rutas que atraviesan varias regiones han llevado a la UE a reorientar sus estrategias hacia instrumentos más interregionales adoptando la noción de "rutas de droga"37. De ahí surgió el Programa de la "Ruta de la cocaína”38 creado en 2011 y financiado inicialmente por el Instrumento de Estabilidad de la UE ${ }^{39}$. Esta iniciativa tiene como objetivo combatir el tráfico de la cocaína coordinando las acciones de los cuerpos y fuerzas de seguridad y el poder judicial de América a Europa a través de países de África Occidental. La acción incorpora el programa de Aeropuertos (AIRCOP), el control de Puertos Marítimos (SEACOP), el proyecto AMERIPOL para mejorar las capacidades de las autoridades policiales, y el proyecto GAFISUD contra el lavado de dinero y crimen organizado. Además, el proyecto CORMS tiene como objetivo para mejorar las sinergias entre todos los elementos del programa de Ruta de la Cocaína. El proyecto más nuevo es CRIMJUST que se estableció mediante un acuerdo entre la UE y la ONUDD de 24 de diciembre de 2015 con el objetivo del fortalecimiento de la cooperación en investigaciones criminales y justicia penal en la Ruta de la Cocaína. Es un proyecto de cuatro años en países seleccionados de África Occidental, América Latina y el Caribe, y su implementación se va a llevar a cabo en colaboración con INTERPOL y Transparencia Internacional. Este proyecto complementa los demás proyectos del Programa Ruta de la Cocaína. Esta iniciativa es un primer intento de abordar el tráfico ilegal a través de la cuenca del Atlántico con tres regiones involucradas superando el corsé de las estrategias regionales.

Dentro de este ámbito de la cooperación entre los países de la UE y de ALC para la lucha contra el crimen organizado otro instrumento principal fue la puesta en marcha del ambicioso programa COPOLAD el 31 de enero de 2011 y que ya está en la segunda fase ${ }^{40}$. Con él se pretende dar coherencia a la cooperación en materia de política de drogas basada en cuatro componentes: consolidación del mecanismo de coordinación existente, el fortalecimiento de los observatorios nacionales de drogas en ALC y la creación de capacidades en el campo de la reducción de la oferta y la reducción de la demanda, respectivamente. El fortalecimiento del mecanismo de diálogo incluye la realización de conferencias y talleres de formación para mejorar el conocimiento y el intercambio de buenas prácticas. El fortalecimiento de los Observatorios incluye la revisión de los indicadores recogidos por la CICAD, de la parte latinoamericana, y el Observatorio Europeo de la Droga y las Toxicomanías (OEDT), por parte europea, así como los de observatorios nacionales o de otros organismos que trabajan en la materia con el fin de buscar una síntesis, mejorar los mecanismos de recogida de información y su procesamiento y desarrollar herramientas metodológicas que ayuden a solventar las carencias existentes.

En la reducción de la demanda, el objetivo es ayudar a identificar las prioridades y a implementar un sistema interactivo de apoyo a la planificación, aplicación y evaluación en progra-

37 El concepto de ruta define "el movimiento que se realiza desde el cultivo ilícito hasta los puntos de entrada de droga al mercado europeo e incluye tanto a países productores como los países en tránsito” (Comisión Europea, 2010).

38 http:/www.cocaineroute.eu/sobre-nosotros/

39 Establecido en 2007, el Instrumento de Estabilidad fue rebautizado en 2014 al Instrumento en Pro de la Estabilidad y la Paz.

40 La primera fase duró hasta 2015 y la segunda iniciada en 2016 durará hasta 2019. La primera fase íntegramente financiada por la UE recibió 6,5 millones de Euros, la segunda contará con 10 millones.

\section{Las redes de} narcotráfico están cada vez más transnacionalizadas en rutas que atraviesan varias regiones 
mas. Con él se trata de mejorar y facilitar el acceso a la información basada en la evidencia que sea de utilidad para responsables de la toma de decisiones, administradores públicos y profesionales del ámbito de la reducción de la demanda y consensuar un conjunto mínimo de estándares de calidad. En el ámbito de reducción de la oferta se trata de reducir la dependencia de la coca de las poblaciones en las áreas afectadas por el cultivo. Para ello se han realizado estudios sobre casos específicos con el fin de determinar buenas prácticas, se han realizado foros de intercambio y se han publicado guías que sirvan para el diseño de nuevos programas de desarrollo alternativo.

El documento de acción de COPOLAD II $^{41}$ hace una valoración positiva de la experiencia y resalta la necesidad de profundizar algunos de los aspectos que se incorporaron en la primera fase: en primer lugar la necesidad de que el enfoque de desarrollo sostenible se aplique a todas las actividades de desarrollo alternativo. Se señala que las intervenciones de desarrollo rural dirigidas a disminuir la producción y tráfico de cocaína y al desmantelamiento de laboratorios clandestinos han de tener en cuenta los aspectos ambientales, el desarrollo social y la sostenibilidad económica. El enfoque de género ya fue introducido con una conferencia anual dedicada exclusivamente a la dimensión de género en la primera fase del proyecto. COPOLAD II debe introducirla como una cuestión transversal y todas las actividades tendrán que incluir un análisis de género y su progreso mediante un informe anual. Otro principio fundamental es adoptar el enfoque de buen gobierno y el respeto a los derechos humanos como principio de todas las intervenciones.

Las actividades de desarrollo alternativo se han realizado sobre todo a través de programas bilaterales con los países más afectados por el cultivo ilícito. La Unión Europea y sus Estados miembros son los principales donantes para ese tipo de proyectos en América Latina. Muchos de ellos han sido realizados en colaboración con la ONUDD que promueve ese tipo de iniciativas. Perú ${ }^{42}$, Bolivia $^{43}$ y Colombia ${ }^{44}$ han sido los principales receptores. En 2006 el grupo de trabajo horizontal sobre drogas del Consejo Europeo aprobó la perspectiva europea sobre desarrollo alternativo en la que se señalaban como supuestos susceptibles de ser beneficiarios de dichos programas "cuando el cultivo ilícito existe, cuando el cultivo ilícito ha existido y podría volver y cuando el cultivo ilícito puede darse si no se toman acciones o cuando personas pueden optar por migrar hacia actividades y áreas de cultivos ilícitos” (Comisión Europea, 2010).

Generalmente en la práctica, estos programas de desarrollo alternativo no se han centrado exclusivamente en ayudar a la sustitución de cultivos. También han incluido, entre otros, programas de monitoreo y de formación profesional para el aprendizaje y la práctica de mecánica, electricidad, procesamiento de alimentos, informática y gestión comercial, entre otros. Pero no todos los programas han conseguido el principal objetivo, que es ofrecer una alternativa suficiente a los cultivadores de coca. La incidencia global en el desarrollo sostenible es baja y con una gran heterogeneidad e intensidad según la zona, el volumen de la financiación y, sobre todo, el grado de compromiso de los gobiernos y las comunidades afectadas. En lo que sí se

41 file:///F:/final-ad-aap-2014-copolad.pdf

42 Por ejemplo el Programa PRODAPP en las áreas de Pozuzo y Palcazu.

43 Como el proyecto APEMIN I y II de apoyo a la pequeña explotación minera o el proyecto Jatun Sacha en el trópico de Cochabamba y los proyectos PRADEAC y PRADEVAT.

44 Destacan los laboratorios de Paz en Magdalena Media, Norte Santander, Oriente antioqueño y Macizo Colombiano y el Programa Familias Guardabosques (PFGB) y el Programa Proyectos Productivos (PPP).

\section{El enfoque de género fue introducido con una conferencia anual dedicada exclusivamente a la dimensión de género}


diferencia el enfoque europeo del de Estados Unidos es en el rechazo a la erradicación forzosa ya que tiende a generar más violencia y el desplazamiento de los cultivos a otras zonas.

En el caso de Bolivia, la consolidación del Gobierno del MAS encabezada por el presidente Evo Morales propició un cambio de estrategia desde la financiación de proyectos más tradicionales hacia un enfoque de apoyo presupuestario sectorial que se basa en un enfoque más integral de desarrollo rural. Las intervenciones se basaron en dos máximas: el no-condicionamiento de la erradicación previa de los cultivos de coca y la no criminalización de los pequeños agricultores (Addicks, Hübner-Schmid \& Cabieses, 2010). Con ello se disminuyó de manera considerable la conflictividad social que había caracterizado los periodos anteriores en que dominó la estrategia de erradicación forzosa financiada por los Estados Unidos. Sin embargo, las evaluaciones realizadas muestran que aún hay problemas para la implementación de los programas debido a la debilidad institucional, las grandes y persistentes desigualdades sociales y los recursos limitados empleados lo cual denota que la prioridad política que se le ha otorgado es insuficiente. También se constató que no se ha dedicado la atención necesaria a los aspectos medioambientales (Addicks, Hübner-Schmid \& Cabieses, 2010). Por ello, la política de desarrollo alternativo en Bolivia pretende insertarse en el marco de la estrategia país que conduzca a la mejora de la cohesión social implicando a las organizaciones sociales en la gestión de los programas y proyectos. Sin embargo, ha habido una cierta tendencia a priorizar los aspectos de ejecución de obras, sin prestar suficiente atención a la capacidad de gestión y se ha creado una cierta dependencia de la financiación externa que afecta a la sostenibilidad de los proyectos.

En Perú la Estrategia Nacional de Lucha Contra las Drogas (2011-2016) ${ }^{45}$ ha puesto en marcha un Plan de Impacto Rápido Desarrollo Alternativo Integral y Sostenible (PIRDAIS) que busca no sólo sustituir los cultivos de coca, sino, llevar la presencia del Estado y promover la articulación entre los diversos sectores del mismo, (Salud, Educación, Agricultura, Justicia, Ambiente, etc.) involucrando a la sociedad civil (empresas, ONGs, iglesias, asociaciones de base etc.). La Comisión Nacional para el Desarrollo y vida sin Drogas (DEVIDA) junto al Ministerio de Relaciones Exteriores coordina la cooperación con la Comunidad Internacional ${ }^{46}$. Las experiencias previas tuvieron un alcance limitado en cuanto a los beneficiarios y generaron críticas por el tipo de cultivos extensivos poco apropiados a las zonas de bosque amazónico que afectan a su ecología y la falta de mercados locales (Cabiesses, 2010). Las experiencias más recientes muestran que, si bien se ha producido un descenso de la dependencia del cultivo de la hoja de coca en las regiones afectadas, aún existen muchos problemas a la hora de garantizar los ingresos de las familias debido a la oscilación del mercado de productos como el café o el cacao. También se observan dificultades a la hora de mejorar la productividad y de organizar asociaciones de productores que puedan mejorar su capacidad de negociación (DEVIDA, 2014).

En el caso de Colombia, el desarrollo alternativo ha estado muy condicionado por la persistencia del conflicto armado del Gobierno con las guerrillas insurgentes de las FARC-EP y del ELN. Las experiencias de los "Laboratorios de Paz fueron programas pilotos con resultados positivos, pero no lograron ni la disminución global de los cultivos, ni el desplazamiento a otros territorios fuera del alcance de las instituciones y las políticas nacionales de desarrollo. En la

\section{En lo que se}

diferencia el enfoque europeo es en el rechazo a la erradicación forzosa ya que tiende a generar violencia y el desplazamiento de los cultivos a otras zonas

\footnotetext{
45 http://www.peru.gob.pe/docs/PLANES/11793/PLAN_11793_Estrategia_Nacional_de_Lucha_contra_las_ Drogas_2012-2016_2012.pdf (visto 2/11/2016).

46 La UE financia el programa de desarrollo alternativo en Satipo - DAS, mediante Convenio de Financiación previsto entre diciembre 2011 y diciembre 2017.
} 
práctica, la lógica de la lucha militarizada contra el conflicto armado dominó las políticas antidrogas nacionales dejando poco espacio a las propuestas de Desarrollo alternativo (Molano, 2010). El Acuerdo de Paz en Colombia acordado por el gobierno del Presidente Santos y las Guerrilla de las FARC-EP47 que fue propuesto a referéndum propone que la guerrilla desmovilizada de las FARC colabore en el desmantelamiento de las redes del narcotráfico vinculándolo a la implantación de una política de desarrollo rural integral. Es una oportunidad para que se busque dar un nuevo enfoque al desarrollo alternativo, de lo contrario se puede contribuir a extender el problema aún más por la región. Para ello se necesitará involucrar de forma efectiva a la población afectada para pasar de una economía de guerra a una economía de Paz.

\section{La ocasión perdida de la UnGASS}

La mencionada sesión especial de la Asamblea General de las Naciones Unidas sobre las Drogas, UNGASS, celebrada en abril de 2016 se adelantó tres años a lo previsto por iniciativa de un nutrido grupo de países entre los que se encontraban muchos latinoamericanos. El plan de acción de 2009 caducaba en 2019, pero en septiembre de 2012 los presidentes de Colombia, Guatemala y México hicieron un llamado a la ONU para que se debatiera la necesidad de una reforma de la estrategia imperante. De ahí que el 20 de diciembre de 2012 a instancias de México con el respaldo de 95 países se adoptó una resolución para adelantar la convocatoria ${ }^{48}$. En la declaración se reconoce que "pese a los redoblados esfuerzos de los Estados, las organizaciones competentes, la sociedad civil y las organizaciones no gubernamentales, el problema mundial de las drogas sigue poniendo en grave peligro la salud y la seguridad públicas y el bienestar de la humanidad" y además socava la estabilidad socioeconómica y política, así como el desarrollo sostenible. Se constataba también el aumento a nivel mundial del uso de drogas y la proliferación de nuevas sustancias, así como "la creciente complejidad de los grupos de delincuencia organizada transnacionales que las fabrican y distribuyen”.

A la tercera UNGASS dedicada a las drogas celebrada en Nueva York se llegó con un documento ya consensuado previamente negociado en la Comisión de Drogas Narcóticas (CDN) de Naciones Unidas con sede en Viena, Austria, y que fue aprobada de forma expeditiva el primer día de la conferencia, antes de realizarse los debates. Este procedimiento fue criticado por su falta de transparencia por parte de la sociedad civil. En realidad, es el resultado de tratar de preservar los resultados de un frágil acuerdo entre posiciones muy diversas que se pusieron de manifiesto durante las sesiones posteriores (IDPC, 2016). La declaración parte de la premisa del respecto a las convenciones vigentes que tienen una visión del tratamiento del tema de carácter prohibicionista, sin embargo, varios participantes en los debates, incluido Werner Sipp, presidente del Comité de control internacional de Narcóticos, defendieron que eso no significaba la necesidad de encarcelar ni aplicar penas drásticas a los poseedores de pequeñas cantidades ni a los consumidores. El rechazo a la pena de muerte, que se aplica en varios países a los delitos relacionados con el narcotráfico no llegó a ser incorporado a la declaración. Sin embargo, sí fue importante la introducción de la llamada al respeto a los derechos humanos en todos los ámbitos de las políticas sobre drogas y la necesidad de que las penas fueran proporcionales a los delitos co-

47 Sometido referéndum el 2 de octubre de 2016, fue rechazado por la población 49.78\% de votos a favor y un $50.21 \% \%$ de votos en contra del acuerdo. Sin embargo se sigue en negociaciones para reformarlo de forma que pueda ser definitivamente implementado.

48 http://www.un.org/es/comun/docs/?symbol=A/RES/67/193 
metidos. También se menciona reiteradamente la flexibilidad de interpretación que dejan las Convenciones a los Estados en las regulaciones nacionales, aunque eso es un arma de doble filo, ya que permite legislaciones más laxas, pero también otras más punitivas (IDPC, 2016).

Otro de los aspectos positivos destacables fue la incorporación a los debates de la Organización Mundial de la Salud (OMS) que puso el acento en la necesidad de un abordaje del tema en clave sanitaria que incorpore el principio de reducción del daño. A pesar de ello, la mención a las terapias de suministro de metadona o de distribución de jeringuillas siguió siendo substituida por eufemismos debido a la oposición de varias delegaciones, que siguen considerándolas inaceptables (IDPC, 2016). En los debates de la UNGASS también se abordó la necesidad de incorporar los programas de desarrollo alternativo en la agenda de desarrollo global del los Objetivos de Desarrollo Sostenible (ODS) aprobada por Naciones Unidas para el periodo 20132015. En este sentido también se señaló la necesidad de destinar la financiación adecuada a los programas de desarrollo sostenible dentro de estas estrategias de desarrollo alternativo. Sin embargo, se omitió que el principal problema de todas las experiencias de desarrollo alternativo hasta la actualidad es que difícilmente pueden ofrecer alternativas reales a la rentabilidad que proporciona el cultivo de coca mientras éste siga siendo un cultivo ilegal y, por tanto, regido por las leyes del mercado negro.

A pesar de las críticas de las ONG a la forma en cómo se adoptó la declaración, la gran movilización social ha sido uno de los hechos positivos más destacables. En diciembre de 2014 ya se creó un Grupo de trabajo de la sociedad civil para la UNGASS 2016 por iniciativa de los comités de ONG sobre Drogas de Nueva York y Viena. El resultado de las consultas fue sometido a los trabajos preparatorios aunque después la participación directa en los debates fue muy limitada (IDPC, 2016). No obstante, el amplio debate que ha generado sin duda ha abierto una vía a la incorporación de nuevos enfoques a través de las demandas de la sociedad civil.

A pesar de los ligeros avances, uno de los principales problemas de la declaración es que no se asume el fracaso de las estrategias seguidas hasta la actualidad, ya que no se ha conseguido reducir la producción, el consumo, ni el tráfico a nivel global. A lo sumo se ha conseguido una reducción en algunos lugares que ha conducido a un desplazamiento hacia otros, el conocido "efecto globo" con lo que se produce una extensión del problema a otros territorios más vulnerables. En general, tanto en la UE como en ALC hay un convencimiento de que el actual sistema no funciona y que hay que dar una respuesta más matizada y equilibrada que atienda, no sólo a la oferta y a la demanda, sino a los aspectos relacionados con el desarrollo y las políticas sociales, incluyendo la sanitaria (Tokatlian y Comini, 2016). América Latina y Europa son un grupo de países productores y consumidores (ambos) suficientemente numeroso como para que una acción más coordinada tuviera un impacto importante en el plano internacional.

Pero a la hora de defender las medidas concretas no hay consenso y acaba imponiéndose la continuidad del statu quo. Aunque algunos países han despenalizado el consumo de algunas sustancias narcóticas que se consideran blandas, como el cannabis, el esquema global sigue siendo el mismo. Durante la convención, varios representantes de la UE y de ALC se pronunciaron a favor de la descriminalización y la reducción del daño pero tampoco hubo una unanimidad en aspectos concretos y sustanciales (Tokatlian \& Comini, 2016). En todos los proyectos de cooperación entre la UE y ALC arriba mencionados se observan avances en materia de principios y en armonización de instrumentos y coordinación de la cooperación en los que la división tradicional entre países consumidores y productores se diluye. El consumo está creciendo en el Sur y las drogas sintéticas se están produciendo masivamente en el Norte. La UE reconoce que es el

\section{A pesar de los ligeros avances, uno de los principales problemas de la declaración es que no se asume el fracaso de las estrategias seguidas hasta la actualidad}


origen de la producción de grandes cantidades de drogas, incluido el cannabis, pero sobre todo de las drogas sintéticas esta en Europa y también es la fuente de gran parte de los precursores necesarios para la fabricación de cocaína que luego va al mercado europeo.

Por lo tanto, parte de su responsabilidad compartida es controlar mejor el destino de los precursores y la producción de drogas sintéticas, para lo que hace falta la cooperación de los sectores público y privado. En los mecanismos de cooperación entre la UE y ALC prevalecen los mecanismos de control para mejorar la lucha contra el narcotráfico, pero en el debate de fondo sobre cómo abordar las políticas nacionales específicas de reducción de oferta y demanda subsisten discrepancias. El aumento de adiciones, tanto en el Norte como en el Sur, requieren tener en cuenta también las consecuencias para la salud de la población, pero las políticas de reducción de daños aún están muy poco desarrolladas en América Latina donde se requiere una mejora sustancial de los servicios públicos sanitarios en general que precisa de recursos significativos.

La lucha contra el tráfico de drogas y el crimen organizado seguirá siendo uno de los temas principales en cooperación interregional, que es esencial por su naturaleza transnacional. Iniciativas trilaterales de cooperación como el Programa de ruta de la cocaína deberían mejorarse de una forma más amplia con una perspectiva más integral de la seguridad humana, incluidas las causas del consumo y que incluya a la protección de las personas en el corazón de las políticas. Si los objetivos de las estrategias contra el tráfico de drogas surgen dependiendo de las causas y no sólo enfocadas al combate sobre las consecuencias, se debería asegurar la coherencia de la agenda de seguridad con las estrategias de desarrollo.

Un paso clave es dar mayor legitimidad a las decisiones, la participación de más actores, ampliando el diálogo, tanto en el diseño y la implementación de políticas de desarrollo como en los aspectos que afectan a la seguridad de las personas. Por ello, uno de los aspectos menos desarrollados en la práctica, pero que se está convirtiendo en una prioridad es la seguridad ciudadana y la lucha contra la delincuencia violenta, que se ha convertido en uno de los principales desafíos que enfrenta ALC. Esto implica la necesidad de incorporar los asuntos de justicia e interior en el debate sobre el diálogo sobre el combate al problema mundial de las drogas. La convergencia de objetivos, sin embargo, no debe conducir a una confusión de los instrumentos; las políticas de seguridad no deben sustituir a las políticas de desarrollo sino que deben coordinarse, pero no confundirse, e incorporar ambas el respeto a los derechos humanos y políticas de desarrollo que atiendan a las causas de los conflictos sociales.

Las declaraciones en las Cumbres biregionales UE-ALC y los Diálogos políticos contra el narcotráfico y el crimen organizado no siempre han ido acompañadas de un compromiso legal y financiero suficientes para hacer frente a los poderosos lobbies financieros y de la industria de armas que permitan frenar la expansión transnacional del crimen organizado. Es un ámbito que precisa una acción de ámbito global y la presión de la sociedad civil. La ONUDD seguirá necesariamente desempeñando un papel clave a nivel mundial. Su labor permite tener un mapa global de la situación del problema de las drogas a nivel global y consensuar estrategias globales, pero para ello necesita la colaboración de los Estados y los organismos regionales. También es fundamental su papel en la elaboración de estrategias conjuntas de alcance global y aunque será difícil llegar a un consenso universal sí se pueden ir introduciendo cambios si se demuestra con experiencias piloto cómo enfoques alternativos tienen mejores resultados que las políticas represivas aplicadas durante decenios. En la misma línea, se ha de reconocer también el valor que tiene la evolución del concepto de desarrollo alternativo y el estudio de su potencialidad 
para abordar las causas profundas del cultivo de drogas, pero difícilmente se podrá erradicar el problema si no se termina con los perversos incentivos del tráfico ilícito.

Para que se den cambios globales es necesario que haya previamente consensos regionales. Es por ello que es importante que ambas regiones, la UE y ALC construyan sus propios procesos regionales y birregionales a través de los mecanismos de diálogo y la cooperación que puedan llevar a posiciones conjuntas ante las instancias regionales, acortando las diferencias que les separan y haciendo realidad el principio de responsabilidad compartida. La UNGASS no fue el punto de inflexión que se esperaba, pero sí ha puesto sobre la mesa cuáles son los principales puntos de las futuras negociaciones que deben dar lugar al nuevo plan de acción global que surja en 2019.

\section{Bibliografía}

Addicks, G., Hübner-Schmid, K. \& Cabieses, H. (2010). Estudio de la intervención de la Unión Europea en la política sectorial de desarrollo integral y de coca en Bolivia (1998-2010). GTZ.

Armenta, A., Jelsma, M. \& Metal P. (2006). Drogas ilegales: la búsqueda del equilibrio. En Freres, C. y Sanahuja, J. A., América Latina y la Unión Europea. Estratégias para una asociación necesaria, Barcelona: Icaria, 453-472.

Ayuso, A. (2014). Oportunidades e limites do diálogo sobre Segurança entre a União Européia e a América Latina. En Mattar, R. y Fracallosi de Moraes, R. (Org.), O Brasil e a Segurança no seu entorno estratégico: A America do Sul e o Atlântico Sul. Brasilia: IPEA.

Ayuso, A. y Viilup, E. (2014). Maritime security in the Atlantic. Atlantic Future Project, European Policy Brief. CIDOB.

Ayuso, A. y Beltrán, S. (Eds.). (2007). Hacia una zona andina de paz: entre la cooperación y el conflicto. Narcotráfico, recursos hídricos compartidos e hidrocarburos. Barcelona: Fundación Cidob.

Bagley, B. (2012). Drug Traffickg and Organized Crime in the Americas: Major trends in the twenty-first Century. Washington: Woodrow Wilson Centre, 21.

Bataller, F. (2000). Consideraciones sobre la Política Exterior de la Comunidad Europea de lucha contra la droga. Revista Española de Desarrollo y Cooperación, 5, 57-75.

Bewley, D. \& Jelsma, M. (2016). UNGAS 2016: Un Consenso roto o a-m-p-l-i-o?. Transnational Institute. Informe sobre Política de Drogas 45.

Cabieses, H. (2010). El 'milagro de San Martín' y los síndromes del 'desarrollo alternativo' en el Perú. TNI. Recuperado de http://www.undrugcontrol.info/images/stories/documents/ brief34s.pdf

Camacho, A. (Ed.). (2006). Narcotráfico: Europa, EE. UU., América Latina. Barcelona: Publicación i Edicions Universitat de Barcelona-OBREAL.

CAN. (2012). Propuesta de Estrategia Andina sobre el Problema Mundial de las Drogas 20122019, 12 diciembre, SG/dt 437.

CICAD. (2015). Hemispheric Report. Evaluation Report on Drug Control. Washington DC: Organization of American States. 
Comisión Europea. (2015). Informe de la CE al PE y al Consejo sobre las avances en la estrategia de la UE en materia de lucha contra la Droga (2012-2020) y en el Plan de Acción en materia de lucha contra la droga (2013-2016) COM (2015) 584 final.

Comisión Europea - Delegación Perú. (2010). La estrategia de la Unión Europea contra las drogas y su aplicación en la Comunidad andina. Revista de la Integración, 6, 17-27.

Contreras, A. (2010). Lucha contra las Drogas y Lucha contra el narcotráfico ¿Es lo mismo? Revista de la Integración, 6, 7-16.

DEVIDA. (2014). Informe de Avance de la Estrategia Nacional de lucha contra las Drogas (20122016). Recuperado de https://www.mef.gob.pe/contenidos/presu_publ/ppr/devida/informe_devida_tramo_fijol.pdf

EMCDDA. (2015). The EU drugs Strategy (2013-2020) and its action plan (2013-2016).

EMCDDA. (2016). Informe Europeo sobre Drogas 2016. Tendencias y novedades.

Global Commission On Drug Policy. (2014). Asumiendo el Control: Caminos hacia Políticas de Drogas.

Gratius, S. (2012). Europa y América Latina: La lucha contra la Droga y el Narcotráfico. Dirección General de Políticas Exteriores, Parlamento Europeo AFET/EUROLAT.

IDPC. (2016). The United Nations General Assembly Special Session (UNGASS) on the World Drug Problem. Report of Proceedings.

Interamerican Dialogue. (2001). ¿Puede adoptarse un enfoque multilateral en la lucha antinarcóticos? Recuperado de http://thedialogue.org/publications/antinarcoticos.asp

International Crisis Group. (2005). Coca, Droga y Protesta social en Bolivia y Perú. Informe sobre América Latina $n^{\circ}$ 12, 38.

Jiménez, C. y Ayuso, A. (2014) El observatorio europeo de las Drogas y las Toxicomanías. En Pi Llorens, M. y Zapater, E., La dimensión Exterior de las Agencias del Espacio de libertad, seguridad y Justicia. Madrid: Marcial Pons,163-182.

Labrousse, A. (2007). La cooperación en materia de drogas entre la Unión europea y América Latina. En Camacho Guizado, A. (Ed.), Narcotráfico: Europa, EE.UU., América Latina. Barcelona: OBREAL, Publicacions i Edicions de la Universitat de Barcelona, 39-59.

Molano, G. (2010). La política de Desarrollo de Alternativo de la Unión Europea en Colombia. Del apoyo a procesos de Paz a la Cooperación con la seguridad democrática. TNI, 20. Recuperado de https:/www.tni.org/es/art\%C3\%ADculo/la-politica-de-desarrollo-alternativo-de-la-union-europea-en-colombia

OEA (2013) Escenarios para el Problema de las Drogas en las Américas 2013 - 2025. Washington DC: OEA, 90.

Pedraza Rosales, H. M. (2014). La regulación del mundo de las drogas desde las experiencias internacionales y la Unión Europea. Revista Multidisciplina, 17, 29-49.

Pi, M. (2007). La acción de la Unión Europea en la lucha contra la droga en la zona andina. En Ayuso, A. y Beltrán, S. (Eds,), Hacia una zona andina de paz: entre la cooperación y el conflicto. Narcotráfico, recursos hídricos compartidos e hidrocarburos. Colección Interrogar la Actualidad. Barcelona: Fundación Cidob, 167-192. 
Ruiz-Cabañas, M. (1998). La OEA y el combate hemisférica contra las drogas. Revista Mexicana de Politica Exterior, 54,102-115.

Thoumi, F. E. (2003). Illegal Drugs, Economy and Society in the Andes. Washington DC: Woodrow Wilson Center Press.

UNDOC. (2016). World Drug Report 2016. Nueva York: Naciones Unidas.

UNDOC. (2010). Desarrollo Alternativo en el área andina. Guía técnica. Viena: Naciones Unidas.

Youngers, C. A. \& Rosin, H. (2004). Drugs and Democracy in Latin America. The impact of US Policy. London: Lyinne Rienner Publishers, Boulder. 